\title{
Special Topic Interoperability and EHR: Combining openEHR, SNOMED, IHE, and Continua as approaches to interoperability on national eHealth
}

Mate Beštek ${ }^{1,2}$; Dalibor Stanimirović

${ }^{1}$ National Institute of Public Health, Ljubljana, Slovenia; ${ }^{2}$ IT University of Copenhagen, Denmark

\section{Keywords}

Telemedicine, Common Data Elements, Knowledge Management, Electronic Health Records, Health information exchange

\section{Summary}

Objectives: The main aims of the paper comprise the characterization and examination of the potential approaches regarding interoperability. This includes openEHR, SNOMED, IHE, and Continua as combined interoperability approaches, possibilities for their incorporation into the eHealth environment, and identification of the main success factors in the field, which are necessary for achieving required interoperability, and consequently, for the successful implementation of eHealth projects in general.

Methods: The paper represents an in-depth analysis regarding the potential application of openEHR, SNOMED, IHE and Continua approaches in the development and implementation process of eHealth in Slovenia. The research method used is both exploratory and deductive in nature. The methodological framework is grounded on information retrieval with a special focus on research and charting of existing experience in the field, and sources, both electronic and written, which include interoperability concepts and related implementation issues.

Results: The paper will try to answer the following inquiries that are complementing each other: 1. Scrutiny of the potential approaches, which could alleviate the pertinent interoperability issues in the Slovenian eHealth context.

2. Analyzing the possibilities (requirements) for their inclusion in the construction process for individual eHealth solutions.

3. Identification and charting the main success factors in the interoperability field that critically influence development and implementation of eHealth projects in an efficient manner. Conclusions: Provided insights and identified success factors could serve as a constituent of the strategic starting points for continuous integration of interoperability principles into the healthcare domain. Moreover, the general implementation of the identified success factors could facilitate better penetration of ICT into the healthcare environment and enable the eHealth-based transformation of the health system especially in the countries which are still in an early phase of eHealth planning and development and are often confronted with differing interests, requirements, and contending strategies.

\section{Correspondence to:}

Mate Beštek

National Institute of Public Health, Trubarjeva 2

1000 Ljubljana, Slovenia

IT University of Copenhagen

Email mate.bestek@nijz.si
Appl Clin Inform 2017; 8: 810-825

received: 18. January 2017

accepted in revised form: 15. May 2017

published: August 9, 2017

Citation: Beštek M, Stanimirović D. Special Topic Interoperability and EHR: Combining openEHR, SNOMED, $\mathrm{IHE}$, and Continua as approaches to interoperability on national eHealth. Appl Clin Inform 2017; 8: 810-825 https://doi.org/10.4338/ACI-2017-01-RA-0011 


\section{Background and Significance}

The sustainability of the Slovenian healthcare system has been a major challenge since its inception [1-3]. The early reforms of the healthcare system have only been partly successful due to major political change and transitional social and economic circumstances [4]. Specific measures were planned to provide the means for its sustainable financing, efficient operation and long-termdevelopment. Nonetheless, the Slovenian healthcare system is still substantially underfinanced and continuously incapacitated in terms of healthcare resources [5]. The majority of parameters concerning human, physical and technological capabilities of the healthcare system still lag behind the Organisation for Economic Co-operation and Development(OECD) average [5]. Operating efficiency, increasing costs, and low throughput of services provided represent the major challenges and limitations $[4,6,7]$. Considerably underexploited is the application of information-communication technology (ICT) in the healthcare environment. Despite early partial digitalization of the healthcare system, Slovenia is still far from an accurate and interoperable information system (IS) which has been of strategic importance in developed countries for improving their health systems [8] and for increasing the social welfare [9] and economic growth [10,11]. Existing ISs have been developed and used within individual healthcare organizations and are adapted to their business processes and needs. This subsequently entails a low degree of interoperability resulting in the fact that complete and timely information is not available. In 2005 Slovenia launched the national eHealth project with the vision of integrating all fragmented ISs and providing the foundation for patient-oriented care $[12,13]$, while the high-quality data should support effective planning, supervision and performance evaluation of individual healthcare organizations and the healthcare system in general $[14,15]$. Ambitious eHealth strategy and goals have proven to be rather difficult to follow and attain in practice. Various obstacles have considerably hindered the development of eHealth, which caused the main gaps in the implementation schedule. Notwithstanding significant delays, the national eHealth project represents a systematic and comprehensive solution. It aims to provide benefits to all stakeholders $[16,17]$ and assist increasingly more critical evidence-based management of the healthcare system $[18,19]$.

In this context, interoperability issues represent obstacles and hindrances of high priority. Healthcare environments have evolved to become ever more specialized and distributed. Health ICT and especially Health Information Exchange (HIE) have enabled convergence by removing the boundaries between the activities, sources, and users of healthcare data and information [20]. This convergence, or better said, alignment can be outlined as a complex multi-level concept named interoperability. Despite the fact that interoperability has traditionally been understood as a very technical term - meaning the ability of different ICT systems to exchange data and to understand the exchanged data meaningfully - it is considered from other non-technical aspects as well. Furthermore, these aspects have become even more important, due to the complexity of healthcare environment, which makes interoperability one of the major burning issues. Successful implementation of interoperable solutions has to support the core idea regarding the accessibility of patient data at any time and place needed. Obviously, a simple solution would be to have one ICT system/source in place globally, but this is very unlikely to happen. Therefore, we need to focus on many different aspects of aligning and integrating existing highly distributed sources of patient data. The core viewpoints or building blocks of this aligned and therefore interoperable health ICT are defined in [21] as: Core technical standards and functions, Certification to support adoption and optimization of health ICT products and services, Privacy and security protections for health information, Supportive business, clinical, cultural, and regulatory environments, and Rules of engagement and governance.

One approach to achieving such alignment is the construction of Enterprise Architecture (EA). Whereas, the alignment has to take place between business level processes and ICT, containing application and data layer. It defines different viewpoints of business and ICT that need to be connected and aligned.

In Europe, a set of specific viewpoints is defined as the European Interoperability Framework (EIF). It defines technical, semantic, organizational, and legal aspects of interoperability, which are supported by a political context [22]. In [23]. The EIF was applied to the domain of eHealth with the eHealth European Interoperability Framework (EEIF), by the addition of eHealth services into the EIF. The underlying fundamental assumptions of EIF are security and privacy, transparency, preser- 
vation of information, reusability, technological neutrality and adaptability, and openness. Also, the EEIF adds eHealth specific patient centricity and use case approach principles.

A special aspect of interoperability in healthcare, that is by itself a far more complex problem than in other domains, is the semantic interoperability [24]. The main activities at this level are standardization of different e.g. terminologies and clinical knowledge models, that represent the common vocabulary and meaning for the ICT systems in order to understand the exchanged data. Also, when talking about interoperability between countries, natural language processing also needs to be considered for the purpose of presenting data and information in different languages. There have been many large projects in Europe that dealt with the issues of semantic interoperability. Their aim was to develop guidelines and artefacts that member states could reuse e.g. epSOS [25], SemanticHealthNet [26], EXPAND [27], PARENT [28], SALUS [29], Trillium [30], Trillium II [31], EHR4CR[32], Antilope [33], TRANSFoRm [34], and eStandards [35].

Interoperability of healthcare ISs supported by a strong and flexible health ICT ecosystem provides the support for transparency and decision-making, reduce redundancy, simplifies payment reform, and facilitates the transformation of care into a new paradigm promoting the concept of ubiquitous health [21]. An interoperable health ICT (IH-ICT) ecosystem makes the right data available to the right people at the right time across services/products and organizations in a way that can be relied upon and meaningfully used by recipients [21].

Conforming to the fundamental assumptions mentioned earlier (e.g. Patient centricity), it is also important to focus on bringing Consumer Health Informatics into the IH-ICT ecosystem $[21,36]$. Integration frameworks [37], which precisely define functional requirements and implementation of core building blocks [38], support such inclusion.

Our previous work on defining an EA framework for IH-ICT in Slovenia is elaborated in detail in [39]. Work presented in [40,41] includes an openEHR based project, and also a document that describes a conceptual plan for the national eHealth in Slovenia based on Integrating the Healthcare Enterprise (IHE) [42]. This work has been the foundation for the core technical standards, functions and certification to support adoption and optimization of health ICT products and services on the national eHealth implementation level in Slovenia. As pointed out in [21], coordinated work on all the building blocks of IH-ICT is a continuous process, whereas the EAframework connects all the components and activities mentioned earlier.

\section{Objectives}

In this article, we present the results regarding IH-ICT elements in Slovenia, as the EHR (Electronic Health Record) introduces the components like the used standards and methodologies, and also provides solid evidence regarding our experience and statistics about the national usage. This includes the lessons learned, recognition and identification of the major obstacles, and elaboration of the strategy used to tackle the emerging challenges. This contains information for all the building blocks introduced earlier - we provide new evidence on technical, semantic, organizational, and legal aspects of interoperability regarding success factors, which were identified and presented in this article.

The main objectives of the paper comprise the characterization and investigation of the potential approaches in terms of interoperability. We focus on openEHR[43], Systematized Nomenclature of Medicine (SNOMED) [44], IHE and Continua Health Alliance (Continua) [45]. We evaluate possibilities for their incorporation into the eHealth environment, and identification of the main success factors in the field, which are necessary for achieving required interoperability, and consequently, for the successful implementation of eHealth projects in general. The paper will try to answer these inquiries that are complementing each other:

1. Scrutiny of the potential approaches, which could alleviate the pertinent interoperability issues in the Slovenian eHealth context.

2. Analyzing the possibilities (requirements) for their inclusion in the construction process for individual eHealth solutions.

3. Identification and charting the main success factors in the interoperability field that critically influence development and implementation of eHealth projects in an efficient manner. 


\section{Methods}

The methodological framework was grounded on information retrieval focusing on research and charting of existing experience in the field, and various electronic and written sources covering interoperability concept and related implementation issues.

We performed the in-depth analysis concerning interoperability problems in the context of the Slovenian eHealth in the second half of 2016. The methodological framework consists of three stages, whereas in each stage we focus on a specific research objective. The first stage involved the investigation of interoperability concept regarding theoretical foundations and a study of the recent and relevant state of the art. Extensive investigation of online resources including strategies, reports, action plans and other forms containing interoperability-related contents were carried out. In the second, experientially oriented stage, our attention was focused on the scrutiny of the experience of previous years, the current situation, and the requirements that arise in related fields, trying to identify the opportunities and the conditions that would enable usage of these approaches in the context of the Slovenian eHealth. As HIE presents the major component of the national eHealth, we considered all four main HIE categories as identified in [38]. Namely, the EHR-EHR data exchange within the same institution (EHR-EHR-SI), EHR-EHR cross-institutional exchange (EHR-EHR-CI), the EHR-PHR exchange ( where PHR denotes Personal Health Records), and the EHR-Clinical Report Form (CRF) exchange (EHR-CRF).

The last stage, deriving from obtained investigation results of the previous two steps, is striving to integrate conceptual and practical aspects and enable identification and charting of the main success factors in the interoperability field, which are critical for the effective development and implementation of eHealth projects.

The in-depth qualitative analysis was conducted combining different techniques [46]. Research methods selection was adjusted to the research field [46,47], given the idiosyncrasy of the interoperability concept and the extent of eHealth initiatives.

\section{Results}

The research results of the first stage of our methodological framework are in line with the main HIE categories identified earlier. They include short introductions to coexisting approaches to interoperability, as it will be illustrated by the experience in Slovenia. The approaches combined in national eHealth project in Slovenia, which is not all truly implemented yet, are the openEHR, SNOMED, IHE and Continua. Table I shows main evaluation points for each approach, while additional introductory notes and descriptions of each approach are provided in the following section.

\subsection{Potential interoperability approaches}

IHE represents a set of profiles, which define most common use cases that occur in the healthcare environment. Such use cases span from the core ICT profiles that define e.g. security, logging, and synchronized time, all the way to the content profiles, whichfocus on data sets. The IHE certifies solution providers for the available profiles. The main focus is thus on technical interoperability and only partly on semantic interoperability. Regarding the presented categories of HIE, it can be said that all the basic IHE certified solutions focus on enabling the transfer of data in organizations and between organizations or domains, and in a very limited set of profiles also the exchange between EHRs and PHRs. IHE defines profiles that consist of agents and transactions between them, which are implemented using existing standards like HL7.

Lack of proper structuring of the content that is being exchanged accounts as one of the major obstacles of IHE. In relevant literature, clinical modeling is discussed by different approaches $[48,49]$. Main strengths of openEHR approach are mainly being open and free, while it can also be used as an applicable interface for existing models [50]. It enables opening of the clinical data models that are typically locked in siloed ICT systems. Such unlocking is the basis for achieving semantic interoperability by following the shared knowledge paradigm. openEHR tooling supports the modeling of core artifacts that are publicly available. As this enables ICT systems to share the definition 
of clinical concepts, a higher level of semantic interoperability can be expected. Lately, HL7 Fast Healthcare Interoperability Resources (FHIR) [51] has gained traction. It is based on the concept of resources, which are a library of models (openEHR models could as well become part of this library). Similarly, openEHR has archetypes and templates. Application of new resource in HL7 FHIR requires new software, whereas in openEHR no new software is needed since a common reference model has to be implemented only once and then new archetypes and templates can be formed or manipulated as they are created HL7 FHIR uses XML schemas, which require changes in the software, dependent upon their change. In addition to the mentioned usage of openEHR archetypes and templates as resources to HL7 FHIR, there is also a simple way of adding HL7 FHIR on top of openEHR by means of developing new application interfaces with HL7 FHIR, which then execute queries against openEHR data. We started using IHE and openEHR in 2010 when HL7 FHIR was not an option but rather the HL7 v3.

OpenEHR is focused mainly on the modeling of clinical data. These models reference clinical concepts and codes from standardized terminologies. The most comprehensive terminology available is the SNOMED. It consists of some 300.000 terms with millions of interconnections. In our case, openEHR and SNOMED are used together. Obviously, there are many more international terminologies being used, and also national and organization specific terminologies, which, by existing, additionally complicate the goal of achieving IH-ICT. We consider SNOMED as the central terminology to which we can map other existing terminologies because it is an ontology, which enables complex relationships between the terms. Also, in one of the notable projects, The European Commission [52], strongly recommended the use of SNOMED.

In theory, openEHR and SNOMED can be used to model clinical data that reference clinical concepts. From these, use case oriented datasets are defined (e.g. Discharge Letter). We can transform such datasets to standardized formats, which are used in the exchange over IHE. Using openEHR and SNOMED to semantically define clinical data, which can be used for exchange over IHE, is the basis for EHR-EHR exchange. Also, the EHR-CRF exchange works in a similar way.

To include the aspect of bringing data from consumer devices, we also evaluate the Continua. Continua is similar to IHE since it also defines profiles. Implementation of profiles uses different existing standards focused on end user devices (e.g. sensors, and measurement devices). The combination of IHE and Continua has previously been explored for the purpose of EHR-PHR exchange of data and was found suitable, despite identified gaps and limitations [53]. In Slovenia and lately also at the European level, Continua and IHE were chosen as the main approaches towards interoperability. In our case, we consider Continua at the national level for the national implementation of telecare. In this way, patients will take measurements at home; the data will be transferred to the national EHR using Continua and IHE. In the EHR, also the openEHR repository will be filled with structured data coming from devices.

In theory, one can expect to support all the categories of HIE by combining these four approaches and also achieving IH-ICT. In terms of interoperability viewpoints, IHE and Continua enable technical interoperability and to a small extent also the semantic interoperability. Adding openEHR and SNOMED to the overall stack is a major step towards semantic interoperability. Authors of [40] have also touched the topic of adding the adaptive clinical process layer and achieving the standardization of processes, which is an evident next step in the future work section.

\subsection{Utilization of interoperability approaches in Slovenia - possibilities, and requirements}

In 2012 Slovenia established the national IHE Technical Infrastructure (IHE TI), which consists of the main IHE profiles. Namely XDS (Cross Enterprise Document Sharing), XUA (Cross-Enterprise User Assertion), XDR (Cross-enterprise Document Reliable Interchange), PDQ (Patient Demographics Query), PIX (Patient Identifier Cross-Referencing), and ATNA (Audit Trail and Node Authentication). In spite having also several IHE content profiles supported in the solution, the first goal was to support only the exchange of unstructured Discharge letters. The solution enabled the sharing of documents, which could be processed only by humans. In 2015, Slovenia upgraded the IHE TI with the goal of supporting semantic interoperability. The methodology used was openEHR. 
Approaches like HL7 v3 have also been trialed out, but it has been empirically confirmed that they require too many resources, not to mention the ambiguity and other issues concerning the underlying HL7 Reference Information Model $[54,55]$. The IHE TI upgrade included an additional IHE certified solution that manipulated openEHR data directly.

Following this openEHR approach, we started a project of establishing the National Patient Summary (PS). We adopted the core dataset from the epSOS [56] project, which is also a recommendation from the European eHealth Network. The PS dataset was reviewed by a group of doctors in Slovenia during the epSOS project. This review represents the much needed professional consensus on the dataset and as such represented the basis for the national PS implementation.

The specification documents within the public call for tender for the implementation of National PS dataset in 2015 required that datasets have to be modeled using openEHR archetypes and templates. Archetypes are focused on modeling clinical recording scenarios by using clinical concepts together with a constrained information model, namely the openEHR Reference Model [57]. Constraints are introduced by using the Archetype Definition Language (ADL) to meet the requirements of a specific clinical record - a template [58]. The platform can automatically produce XML (Extensible Markup Language) Schema and technical specifications that are traditionally used by software developers. It also provides a REST (Representational state transfer)-based interface for more light web-oriented use cases. For the purpose of modeling archetypes and templates, we used the tools Archetype Editor and Template Designer (http://www.openehr.org/downloads/modelling tools).

Overall, eight software providers offer Electronic Medical Record Systems (EMR) in Slovenia. We have contracted all of them to connect their systems to the national PS. Since such integration has previously been implemented (for the purpose of discharge letters), the main requirement was to support the transfer of new data. These schemas are based on openEHR, and existing terminologies - both local and international. Terminologies used were the Slovene version of ICD10, SNOMED$\mathrm{CT}$, and LOINC among others. This project also represents the first national implementation of SNOMED CT subset in Slovenia.

- Figure 1 shows an activity diagram for a simple use case in which a patient uses a device at home to perform a measurement. In addition to the activity steps and actors, we depict different interoperability approaches and artifacts as they are used in order to show how all the interoperability approaches are connected. We can see that Continua profiles cover the transfer of data from devices to a cloud service, which will then produce a Diagnostic Results Document (Results Doc) as an XML/JSON structured document and send it over IHE profiles to the national eHealth (e.g. Electronic Health Record). Here, the Results Doc is validated against the openEHR template, which consists of one or more openEHR archetypes. Different data elements will have to contain codes from various terminologies like LOINC, ICD10, and SNOMED. The national eHealth then sends a notification to the patient's personal doctor that a new measurement is available. He will then use his Electronic Medical Record (EMR) to retrieve the Results Doc in XML/JSON format. This is possible since all the EMR systems are integrated with the eHealth IHE infrastructure.

It is important to stress that we are still working on the introduction of Continua to support the EHR-PHR exchange. Also, we will extend our work towards concepts like ubiquitous health and smart cities with ongoing projects [59].

\section{Identified obstacles}

During this implementation, the major obstacles identified at the level of healthcare providers (HCP) include:

- obtaining a common data set for the PS where government bodies needed to act (time consumption and lack of engagement were identified as the main issues concerning this matter),

- obtaining consensus from doctors on the dataset, which is often very time-consuming and medical professionals very often require extra funding for such projects,

- the creation and usage of the PS influences existing business processes in the healthcare system, meaning it is necessary to get the support from the management at HCPs and $\mathrm{MoH}$,

- the implementation had to use terminologies that were already in use - SNOMED-CT was in turn used on a much smaller scale to what was planned; also, the inclusion of existing terminology custodians in the process of common dataset preparation was a prerequisite, 
- software providers had different data models in their systems, and they were not willing to change their solutions for the purpose of PS - obviously, also the user interface changes were connected to the changes of data models,

- another national implementation of a vaccination registry was conducted in parallel to the PS project. The PS contained the actual vaccination section as a subset; therefore any change in the vaccination dataset was manifested as a change in the PS project; this co-dependency between two national projects was another source of complexity with the PS implementation,

- Integration with the hospitals and other HCPs was a part of the public call for tender in which we acquired and established the IHE-TI. Each of the software companies had implemented application interfaces to IHE-TI. Now, when a new set of data is defined, they only work on implementing new XML schema (generated from openEHR templates) for sending the data,

- in spite of having the technical integration established, hospitals and other providers did not just start sending documents. Slovenia in 2015 changed the Healthcare Databases Act that was expanded with eHealth (defined as the national healthcare information system) and all eHealth solutions have become national databases. Especially the Central registry of patient data (CRPD / EHR), became obligatory for the HCPs,

- Despite the Healthcare Databases Act from 2015 defined the usage of national EHR as obligatory, we still do not have all the HCPs sending and receiving documents. This is still an ongoing process.

\section{Requirements for inclusion of the interoperability approaches}

For the national PS like projects to succeed, they must meet several requirements. These include at least:

- a strong core healthcare informatics team that oversees all of the activities and is competent to participate and also takes custody of the subject matter including healthcare specific standards and methodologies is a prerequisite; this also includes a strong emphasis on clinical modeling and terminology management on a national level,

- a project specific or national board of healthcare professionals that take part in the consensus development, which can also include participation in clinical modeling and terminology governance,

- the support of the management of all the main stakeholders - HCPs management, MoH, health insurance fund,

- continuous presence in the media with the purpose of informing and education different user groups,

- strong technical standards based (IHE, Continua) infrastructure in place enables the standardized exchange of data between the various nodes in the healthcare system,

- quality contracts with private companies that are strategically important for the national eHealth,

- open public calls for tendering for the development of new solutions,

- certification of the solutions is highly needed and

- the internal organization needs to support such dynamic cooperation with different entities, so moving the organization to the more agile way of work is strongly suggested.

Following from these particular experience from the past years, we additionally reviewed existing literature to obtain more generalized success factors that influence the effectiveness of the eHealth implementation.

\subsection{Identification of the main success factors in the interoperability field}

In examining the possibilities and requirements for the inclusion of depicted approaches into the Slovenian eHealth context, we have identified several success factors with enough influence potential for the effective execution of interoperability principles and implementation of eHealth projects in general ( Tab. 2). 
Success factors meaning appropriate and balanced dynamics between healthcare ecosystem conditions and elemental eHealth requirements were identified by primarily focusing on critical aspects of the development and implementation of eHealth projects.

Accordingly, and in compliance with existing frameworks; the political, regulatory, institutional, and technological areas where identified as having the most influence on eHealth. Depending on the recent experience in the eHealth development and implementation process, we mapped a list of success factors for each area. The effectiveness of the application of these factors is strongly connected with the general development level of eHealth projects and presents a highly likely mechanism for identifying successful countries in the digitalization of healthcare systems. In Table II, all the factors grouped into the four identified areas are presented. Evidence suggests that some of the identified success factors hold more influence regarding not only raising the overall success rate of eHealth projects but also alleviate the shortcomings of other success factors. It is clear that only versed operationalization and coordination of the success factors can support effective development and implementation of eHealth projects.

The chosen interoperability approaches have positively influenced the implementation of new national documents both for the government and for the ICT solutions providers in Slovenia. The development cycles have become shorter and agiler. This is clearly depicted in $\mathbf{F i g u r e} 2$ that shows the number of documents available in the national eHealth in 2016. The number of records is the direct result of using the IHE, openEHR and SNOMED approaches to interoperability. In $>$ Figure 3 we see the number of distinct patients that have at least one document available in different eHealth solutions (eReferral, ePrescription, and the CRPD). Also, in $>$ Figure 4 we see how well a particular solution reaches the overall population $(2 \mathrm{M})$. For the eReferral, we can see that it reaches $18 \%$ of the population while ePrescription and CRPD reach $79 \%$ and $48 \%$ of the population respectfully. In overall, more than $84 \%$ of the population has at least one document available in the national eHealth.

\section{Discussion}

Combining and applying different approaches to alleviate the interoperability issues is a very challenging undertaking. Lack of first-hand empirical studies that would systematically map and analyze different interoperability approaches and their prospective incorporation into the planning, development, and implementation of national eHealth projects intensifies the challenge even more. Furthermore, we can observe the limited focus of the majority of the relevant research efforts in the field that highlight only a small number of views on interoperability and their influence on the operation of specific ICT solutions or provision of distinct healthcare specific ICT services. This situation considerably impedes research on interoperability in healthcare ICTs. Also, it additionally complicates the formulation of a coherent platform, that would provide practical support in further efforts towards the innovative application of existing interoperability approaches (such as openEHR, SNOMED, IHE, and Continua) in the planning, development, and implementation of national eHealth projects.

Albeit precise outlining and characterisation of the applicability as well as final long-term effects of the interoperability approaches mentioned above are difficult, we can rather describe a few outcomes from an early stage. Based on the eHealth project structure and the solutions available thus far, the adequate use of proposed interoperability approaches is likely to have a positive effect on all main elements of the eHealth development and implementation. The effective application of interoperability approaches should consider the multitude of influences from the healthcare ecosystem that may adversely affect their integration into the healthcare IS. This situation calls for a new definition of the behavior of the principal agents in the healthcare system, and the new arrangement of the infrastructural, organizational, and technological elements that support the interoperability requirements.

Strategic sources of Slovenia [3,60] focus on improved coordination of actors in the healthcare system, patient centeredness, quality of health services, financial sustainability and transparency, and standardization, simplification, and optimization of the healthcare processes. These attributes 
present the verification framework regarding the importance of interoperability principles, which should represent the foundation of the future health IS.

However, the whole transformation towards the interoperability has to be adequately arranged taking into consideration all the complexities. The successful introduction of interoperability principles clearly requires government incentive, engagement of all stakeholders, and their agreement on the various and often antagonistic issues within the healthcare system.

Despite sensitivity to subjectiveness and different interpretations, our in-depth analysis provides a valuable view of the interoperability concerns and their profound effects on the general success of eHealth projects development and implementation. The main limitations of the study probably concern the interoperability approaches that we chose arbitrarily, as well as the fact that we defined their applicability on the basis of internal examination and sources investigation without experimental testing and validation of each interoperability approach in practice. Accordingly, the questions of interoperability approaches' quality and suitability can be questioned, and the results of the conducted in-depth analysis may, therefore, be open to different interpretations. These concerns should be further addressed in future research and successive experiments following the main idea of defining a theory-based framework for the analysis of interoperability issues in the national and international context. Despite some potential methodological shortcomings and restricted resources, our in-depth analysis exposes critical dynamics of interoperability and its wide-ranging effects on the general success of eHealth projects. The identified success factors may be used as a practical starting point for the planning of project coordination, advance activities, required material and non-material resources as well as the amount of necessary managerial effort.

\section{Conclusions}

Pervasive penetration of ICT solutions into the healthcare processes in the last decades has made existing IS development practices being questioned. The presented research does not focus on providing a magic stick solution for the interoperability concerns related to planning, development, and implementation of eHealth projects, but attempts to establish a ground for addressing interoperability concerns, and identification of the most important success factors for their alleviation.

The obtained results could help identify the required actions and indicate the appropriate measures for the inclusion of the adequate interoperability approach into the whole eHealth project development and implementation cycle. Provided insights and identified success factors could become part of the strategic starting points for continuous integration of interoperability principles into the healthcare domain and more efficient ICTs inclusion, especially in the countries which are still in an early phase of eHealth planning and development. Also, issues discussed could support the much-needed change in the ISs development area and promote further steps towards the general interoperability in the national and international healthcare environment.

The presented research provides the comprehensive analysis of existing configurations and may serve as the grounds for further steps in this area. Despite system considerations and related difficulties, the introduction of interoperability approaches in the Slovenian eHealth project, and most likely elsewhere, represents a development opportunity. To secure improved utilization of healthcare resources and provide real public health benefits, it is of utmost importance to focus on coordination of eHealth with other ecosystem factors and pending structural reforms of the Slovenian healthcare system.

\section{Questions}

Q1: What is the optimal approach to national eHealth implementation?

1. An optimal approach to national eHealth implementation is based on identification and implementation of success factors on a national level.

2. The approach based on a technological interoperability framework is needed since technology is the main critical element of national eHealth implementation. 
3. Focusing on appropriate implementation of ICT solutions and adequate funding is the best approach.

4. Since health professionals and citizens are the main users of eHealth solutions, it is best to focus on the promotion of eHealth and education of these two major end user groups.

Explanation of the correct answer to Question 1: answers 2, 3 and 4 represent only a partial set of factors that influence national eHealth implementation. It is of most importance to base the national eHealth implementation on the broad range of previously identified success factors. Therefore, the answer 1 is the correct reply to the first question.

Q2: What is openEHR in the context of interoperability?

1. OpenEHR supports the message based approach to interoperability where the focus is on specifying exactly defined data sets for specific use cases, where the main focus is on the data flow between systems without knowing anything about the internal workings of the affected systems.

2. OpenEHR is an ontology that consists of clinical concepts. Data elements in different messages are mapped to these concepts.

3. OpenEHR is based on the idea of resources. These are a library of different models that can be used to define different data structures for the exchange between systems.

4. OpenEHR supports the single source based approach to interoperability. This includes global models that are freely accessible.

Explanation of the correct answer to Question 2:

- Answer 1 does not describe openEHR, but would better fit the message based approaches like HL7 v2 and v3 where the focus is on defining the data flow between systems without knowing anything about the internal workings of the systems. Answer 1 is not the correct option.

- Answer 2 does not describe openEHR. Such description would fit a terminology like SNOMED better. Terminologies are definitions of clinical concepts which are used for giving meaning to data elements. Answer 2 is not the correct answer.

- Answer 3 is a description of the latest HL7 FHIR approach to interoperability. OpenEHR models could become new resources - elements of the library of models available for different purposes. This answer is not the correct answer.

- Answer 4 is the right answer since openEHR is an example of a single source based approach to interoperability where models are taken outside of existing systems and represent common artifacts that define the meaning of clinical data. As such, they can be used as the basis for transformation to any other of existing messaging formats.

\section{Clinical Relevance Statement}

The interoperable eHealth solutions enable higher quality care for patients, better-informed decision-making for doctors and evidence-based management of the individual healthcare institutions and health systems in general.

Conflict of Interest

The authors declare that they have no conflicts of interest in the research.

Protection of Human and Animal Subjects

The authors declare that human and/or animal subjects were not included in the project.

Acknowledgements

No acknowledgments. 


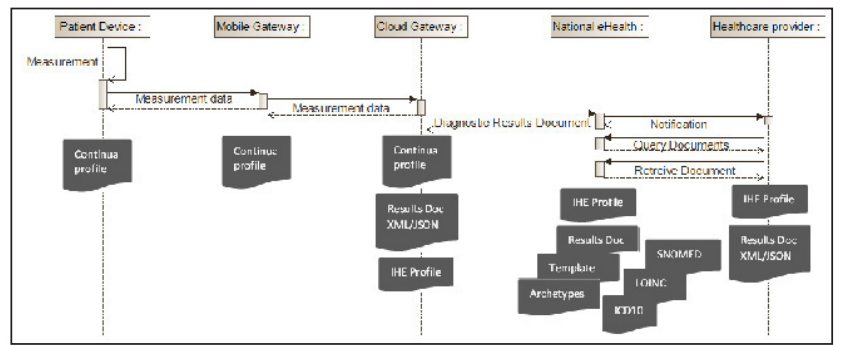

Fig. 1 Mapping interoperability approaches to a simple use case

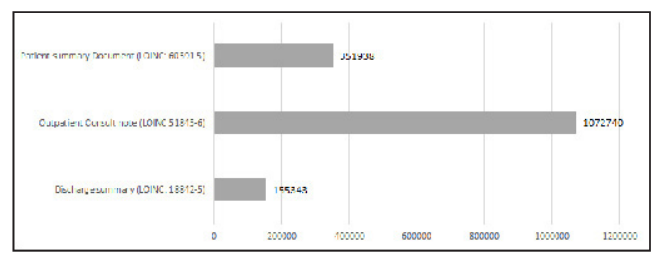

Fig. 2 Number of documents available in the Central Registry of Patient Data (national EHR) on 12/31/2016

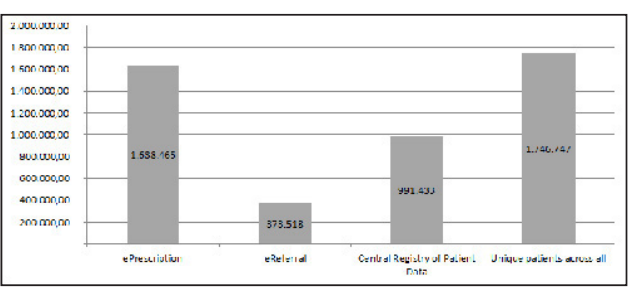

Fig. 3 Distinct number of patients in different eHealth solutions and across all solutions on 12/31/2016

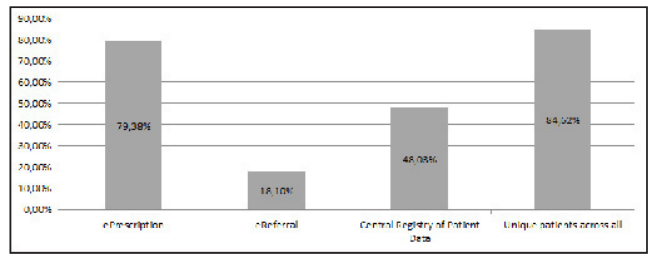

Fig. 4 The share of population reached by the three national eHealth solutions and the proportion over all solutions

on $12 / 31 / 2016$ 
Table 1 Evaluation of interoperability approaches

\begin{tabular}{|c|c|c|c|}
\hline $\begin{array}{l}\text { Interoper- } \\
\text { ability ap- } \\
\text { proach }\end{array}$ & Description & Pros & Cons \\
\hline IHE & $\begin{array}{l}\text { IHE represents a set } \\
\text { of profiles that de- } \\
\text { fine most common } \\
\text { use cases that occur } \\
\text { in the healthcare en- } \\
\text { vironment. }\end{array}$ & $\begin{array}{l}\text { - Standardized use-cases in the healthcare en- } \\
\text { vironment that consist of agents and transac- } \\
\text { tions between them. } \\
\text { - A global approach to interoperability. } \\
\text { - Has become common off the shelf product. } \\
\text { - Supports adding new solutions. } \\
\text { - Promoted to the EU level. }\end{array}$ & $\begin{array}{l}\text { - Not all IHE profiles are in use. } \\
\text { A long learning curve for exist- } \\
\text { ing solution providers. } \\
\text { - We needed a special interface } \\
\text { between IHE infrastructure and } \\
\text { existing solutions in the hospi- } \\
\text { tals. }\end{array}$ \\
\hline Continua & $\begin{array}{l}\text { Similar to IHE but fo- } \\
\text { cused on smaller de- } \\
\text { vices that enable re- } \\
\text { mote measurements } \\
\text { and conveying of } \\
\text { data to e.g. EHR. }\end{array}$ & $\begin{array}{l}\text { - Enables standardization of use-cases focused } \\
\text { on different devices used in healthcare. } \\
\text { - Connection with IHE supported. } \\
\text { - A global approach to devices interoperability. } \\
\text { - Promoted to the EU level. }\end{array}$ & $\begin{array}{l}\text { Devices tend to be more ex- } \\
\text { pensive. } \\
\text { - A long learning curve. } \\
\text { - Support for non-Continua com- } \\
\text { pliant devices are still needed } \\
\text { due to their higher market } \\
\text { share. }\end{array}$ \\
\hline SNOMED & $\begin{array}{l}\text { The largest terminol- } \\
\text { ogy available. It en- } \\
\text { ables modeling clini- } \\
\text { cal concepts that are } \\
\text { used to define se- } \\
\text { mantics. }\end{array}$ & $\begin{array}{l}\text { As an ontology, it enables great concept defini- } \\
\text { tions regarding connections between concepts } \\
\text { and supporting attributes. } \\
\text { Subsetting can be used to use parts of } \\
\text { SNOMED for specific projects - thus supporting } \\
\text { gradual national implementation. } \\
\text { Existing mappings of other terminologies to } \\
\text { SNOMED - e.g. LOINC to SNOMED. } \\
\text { Great support for member countries from the } \\
\text { International Health Terminology Standards De- } \\
\text { velopment Organization(IHTSDO). }\end{array}$ & $\begin{array}{l}\text { More than } 300.000 \text { concepts } \\
\text { represent a complex and ex- } \\
\text { pensive translation projects. } \\
\text { Terminology management sol- } \\
\text { ution is needed for more effec- } \\
\text { tive management. }\end{array}$ \\
\hline OpenEHR & $\begin{array}{l}\text { An approach to mo- } \\
\text { deling data that is } \\
\text { created and used in } \\
\text { the healthcare pro- } \\
\text { cesses. Also, spec- } \\
\text { ifies an architecture } \\
\text { for an EHR. }\end{array}$ & $\begin{array}{l}\text { Supports concepts like open data and open } \\
\text { standards. } \\
\text { Data definitions are publicly available and used } \\
\text { nationally. } \\
\text { - Interfaces to existing terminologies are sup- } \\
\text { ported. } \\
\text { Empowers healthcare professionals, who can } \\
\text { create new e.g. registries (without specific soft- } \\
\text { ware development process) } \\
\text { Enables semantic querying. } \\
\text { The international community around the Ope- } \\
\text { nEHR foundation supports the clinical model- } \\
\text { ing. The results are shared internationally. }\end{array}$ & $\begin{array}{l}\text { - Healthcare professionals are not } \\
\text { motivated to engage in clinical } \\
\text { modeling for various reasons } \\
\text { - Establishing a national editorial } \\
\text { board is both expensive and } \\
\text { hard to achieve. }\end{array}$ \\
\hline
\end{tabular}


Table 2 Main success factors for effective development and implementation of eHealth projects

\begin{tabular}{|c|c|}
\hline Political factors & Regulatory factors \\
\hline $\begin{array}{l}\text { - Political commitment to reform } \\
\text { - Inclusion of stakeholders and effective collaboration } \\
\text { - Realistic agenda and adequate budget } \\
\text { - Strong project management team } \\
\text { - Monitoring and control of project implementation and timely } \\
\text { measures } \\
\text { - Evaluation frameworks and practice } \\
\text { - Promotional campaign, media presentations, and mobilization } \\
\text { of public support } \\
\text { - Regional cooperation and international integration } \\
\text { Projections and vision for the future }\end{array}$ & $\begin{array}{l}\text { - Promoting an enabling legal environment } \\
\text { - Adaptation of existing legislation and secto- } \\
\text { ral laws } \\
\text { - Adoption and implementation of the necess- } \\
\text { ary regulations and code of practice } \\
\text { - Harmonization of national regulation with } \\
\text { international conventions and agreements }\end{array}$ \\
\hline Institu & Technologi \\
\hline $\begin{array}{l}\text { - Restructuring of the healthcare system } \\
\text { - Reorganization of the clinical departments } \\
\text { - Business process reengineering } \\
\text { - Business process and service standardization } \\
\text { - Intra- and interinstitutional agreements, cooperation, and } \\
\text { joint public procurement } \\
\text { - Promoting the use of ICT, education, and training } \\
\text { - Pilot projects } \\
\text { - Contingency plan } \\
\text { - New business model } \\
\text { - Partner relationship and user helpdesk } \\
\text { - Responsiveness to user comments and feedback } \\
\text { - Prompt resolution of problems }\end{array}$ & $\begin{array}{l}\text { - Interoperability framework } \\
\text { - Technological infrastructure } \\
\text { - Enterprise architecture } \\
\text { - Specialized ICT development team and ad- } \\
\text { equate funding } \\
\text { - Transfer of good practice, international ex- } \\
\text { perience, consultancy } \\
\text { - Monitoring and technology watch } \\
\text { - Effective implementation of appropriate ICT } \\
\text { solutions } \\
\text { - Collaboration and testing of ICT solutions } \\
\text { with stakeholders } \\
\text { - Technical adjustments and optimization } \\
\text { - Maintenance, continuity, and development }\end{array}$ \\
\hline
\end{tabular}




\section{References}

1. Pammolli F, Riccaboni M, Magazzini L. The sustainability of European health care systems: beyond income and aging. Eur J Heal Econ [Internet] 2012; 13(5): 623-34.

2. Stanimirovic D. A Framework for Information and Communication Technology Induced Transformation of the Healthcare Business Model in Slovenia. J Glob Inf Technol Manag [Internet] 2015; 18(1): 29-47.

3. Slovenija R. Resolucija o nacionalnem planu zdravstvenega varstva 2008-2013 "Zadovoljni uporabniki in izvajalci zdravstvenih storitev" (NPZV 08-13 ). 2013.

4. Albreht T, Turk E, Toth M, Ceglar J, Marn S, R. PB, Schäfer M, Avdeeva O, Van Ginneken E, European Observatory on Health Systems and Policies WHO. Slovenia - Health system review. Heal Care Syst Transit [Internet] 2009; 11(3): 168.

5. OECD. Health at a Glance 2013. OECD Publ [Internet]. [cited 2013 Nov 24]; Available from: http://www. oecd.org/health/health-at-a-glance.htm.

6. Albreht T. Resolution-the national health care plan 2008-2013. Heal Policy Monit [Internet] 2008; (11): $1-6$.

7. Ministry of Health. Health Care System Upgrade by 2020. Gov Repub Slov Minist Heal [Internet]. 2011;1-17. Available from: http://imeinars.blogspot.co.id.

8. European Commission. eHealth Benchmarking III. Final Report. Smart 2009/0022. 2012;(661818):4-7.

9. Wallace C. Can Information and Communications Technology Enhance Social Quality? Int J Soc Qual [Internet] 2012; 2(2): 98-117.

10.González-Sánchez VM. "Information and Communication Technologies" and entrepreneurial activity: drivers of economic growth in Europe. Serv Ind J [Internet] 2013; 33(7-8): 683-93.

11. Qureshi S. Information and Communication Technologies in the Midst of Global Change: How do we Know When Development Takes Place? Inf Technol Dev [Internet] 2013; 19(3): 189-92.

12. Trudel M-C, Paré G, Laflamme J. Health information technology success and the art of being mindful. Health Care Manage Rev [Internet] 2012; 37(1):31-42.

13. Iveroth E, Fryk P, Rapp B. Information technology strategy and alignment issues in health care organizations. Health Care Manage Rev [Internet] 2013; 38(3): 188-200.

14. Black AD, Car J, Pagliari C, Anandan C, Cresswell K, Bokun T, McKinstry B, Procter R, Majeed A, Sheikh A. The impact of eHealth on the quality and safety of health care: a systematic overview. Djulbegovic B, editor. PLoS Med [Internet] 2011; 8(1): e1000387.

15. Rosenkötter N, Achterberg PW, Van Bon-Martens MJH, Michelsen K, Van Oers HAM, Brand H. Key features of an EU health information system: A concept mapping study. Eur J Public Health 2016; 26(1): $65-70$.

16. Haux R. Medical informatics: Past, present, future. Int J Med Inform [Internet] 2010; 79(9): 599-610.

17. Stanimirović D. Modelling the Health Information System in Slovenia - Operative, Construction and Implementation Aspects. Int J Eng Bus Manag [Internet]. 2015;1. Available from: http://www.intechopen. com/journals/international_journal_of_engineering_business_management/modelling-the-health-information-system-in-slovenia-ndash-operative-construction-and-implementation.

18.Leung RC. Health information technology and dynamic capabilities. Health Care Manage Rev [Internet] 2012; 37(1): 43-53.

19. Bardhan IR, Thouin MF. Health information technology and its impact on the quality and cost of healthcare delivery. Decis Support Syst [Internet] 2013; 55(2): 438-49.

20. Gibson CJ, Dixon BE, Abrams K. Convergent evolution of health information management and health informatics. A perspective on the future of information professionals in health care. Appl Clin Inform [Internet] 2015; 6(1): 163-84.

21. Office of the National Coordinator for Health IT. Connecting Health and Care for the Nation区: A 10-Year Vision to Achieve an Interoperable Health IT Infrastructure 2012; 1-13.

22. Commission E. European Interoperability Framework (EIF) for European public services. Brussels 2010.

23.European Commission, Langenhove P van, Decreus K, Rogala A, Olyslaegers T, Whitehouse D. eHealth European Interoperability Framework - Vision on eHealth EIF. 2013; 64.

24. Roadmap D, Europe FOR. Semantic Interoperability for Better Health and Safer Healthcare [Internet] Journal of Magnetism and Magnetic Materials 2009; 240: 508-510.

25.European Comission. Bringing cross-border interoperability to health care [Internet]. 2011 Available from: http://ec.europa.eu/isa/actions/02-interoperability-architecture/2-12action_en.htm.

26.Semantic Interoperability for Health Network [Internet]. 2011 Available from: http://www.semanti chealthnet.eu.

27.Expanding Health Data Interoperability Services [Internet] 2014 Available from: https://ec.europa.eu/ digital-single-market/en/news/expand-deploying-sustainable-cross-border-ehealth-services-eu. 
28. Cross border patient registries initiative (PARENT) [Internet]. 2012 Available from: http://patientregistries.eu.

29. Security And InteroperabiLity in Next Generation PPDR CommUnication InfrastructureS [Internet]. 2013 Available from: https://www.sec-salus.eu.

30.Trillium Bridge Bridging Patient Summaries across the Atlantic [Internet]. 2013 Available from: http://www.trilliumbridge.eu/.

31.Trillium-II EU/US Cooperation for Global Interoperability in Digital Health [Internet]. 2017. Available from: http://www.i-hd.eu/index.cfm/services/research/trillium-ii/.

32.Electronic Health Records for Clinical Research [Internet]. 2011 Available from: http://www.ehr4cr.eu/.

33. Advancing eHealth Interoperability [Internet]. 2013 Available from: https://www.antilope-project.eu.

34.TRANSFoRm [Internet] 2010 Available from: http://www.i-hd.eu/index.cfm/resources/ec-projects-re sults/transform/.

35.eHealth standards and Profiles in Action for Europe and Beyond [Internet]. 2015 Available from: http://www.estandards-project.eu.

36. Valdez RS, Holden RJ, Novak LL, Veinot TC. Transforming consumer health informatics through a patient work framework: connecting patients to context. J Am Med Informatics Assoc [Internet] 2014; 1-7.

37. Marceglia S, Fontelo P, Ackerman MJ. Transforming consumer health informatics: connecting CHI applications to the health-IT ecosystem. J Am Med Informatics Assoc [Internet] 2015; 22(e1): e210-2.

38. Marceglia S, Fontelo P, Rossi E, Ackerman MJ. A Standards-Based Architecture Proposal for Integrating Patient mHealth Apps to Electronic Health Record Systems. Appl Clin Inf [Internet] 2015; 6(3): 488-505.

39. Stanimirović D. Evaluation of Information Systems and Enterprise Architecture Models in Healthcare. University of Ljubljana 2014.

40. Beštek M, Brodnik A. Interoperability and mHealth - precondition for successful eCare. In: Adibi S, editor. Mobile Health (mHeath) The Technology Road Map [Internet]. New York: Springer 2014.

41. Beštek M, Umer R, Jeras I. Vzpostavitev interoperabilne hrbtenice IS e-Zdravje Konceptualna zasnova [Internet]. 2011. Available from: http://www.mz.gov.si/fileadmin/mz.gov.si/pageuploads/eZdravje/2011/eZ dravje_-_Vzpostavitev_interoperabilne_hrbtenice.pdf.

42.Integrating the Healthcare Enterprise [Internet] Available from: https://www.ihe.net/.

43. OpenEHR.org [Internet] Available from: http://www.openehr.org/.

44.SNOMED [Internet] Available from: http://www.snomed.org/.

45.Personal Connected Health Alliance [Internet Available from: http://www.pchalliance.org/.

46. Yin K R. Case study research: design and methods. 4th ed. Thousand Oaks, CA: Sage Publications 2009.

47. Quinn Patton M. Qualitative Evaluation and Research Methods. 2nd ed. Thousand Oaks, CA: Sage Publications 1990.

48. Blobel B, Goossen W, Brochhausen M. Clinical modeling-A critical analysis. Int J Med Inform [Internet] 2014; 83(1): 57-69.

49. Maldonado JA, Valencia S. Detailed Clinical Models and their relation with Electronic Health Records. Polytechnic University of Valencia 2015.

50. Rector AL, Johnson PD, Tu S, Wroe C, Rogers J. Interface of Inference Models with Concept and Medical Record Models 2001; 1-8.

51.HL7. HL7 Fast Healthcare Interoperability Resources [Internet]. [cited 2017 Mar 7]. Available from: http://wiki.hl7.org/index.php?title=FHIR.

52. Kalra D, Vander Stichele R, Schulz S, Karlsson D, Rosenbeck Gøeg K, Cornet R, Cangioli G, Chronaki C, Thun S, Jaulent M-C, Hämäläinen P, Kronstein Kufrin V, Fathollah-Nejad R, Dewenter H, Volkert P, Melgara M, Stroetmann V. Assessing SNOMED CT for Large Scale eHealth - D4.4 Policy and strategy recommendations - final report. 2015.

53. Urbauer P, Sauermann S, Frohner M, Forjan M, Pohn B, Mense A. Applicability of IHE/Continua components for PHR systems: Learning from experiences. Comput Biol Med 2015; 59: 186-93.

54. Smith B, Ceusters W. HL7 RIM: an incoherent standard. Stud Health Technol Inform 2006; 124(August): 133-8.

55. Browne E. Shortcomings of HL7 Reference Information Model ( RIM ) [Internet]. 2008. Available from: http://docplayer.net/22512528-Shortcomings-of-hl7-reference-information-model-rim.html.

56. Summary P, Version D. Smart Open Services for European Patients Open eHealth initiative for a European large-scale pilot of epSOS Interoperability Framework 2009;

57. Beale T. Archetypes: Constraint-based Domain Models for Future-proof Information Systems. In: Workshop on Behavioural Semantics. OOPSLA 2002.

58. Martinez-Costa C, Menarguez-Tortosa M, Fernandez-Breis JT, Martínez-Costa C, Menárguez-Tortosa M, Fernández-Breis JT. An approach for the semantic interoperability of ISO EN 13606 and OpenEHR archetypes. J Biomed Inform [Internet] 2010; 43(5): 736-46. 
59.EkoSMART Smart Cities and Communities [Internet]. 2016 Available from: http://ekosmart.net/en/ ekosmart-2/.

60. Kodele D, Košir F, Marušič D, Sušelj M, RUSZV P. eZdravje 2010, Strategija informatizacije slovenskega zdravstvenega sistema 2005-2010. 2010. 